\title{
Non-linear analysis of composite parts jointed with embedded adhesive under tensile load
}

\section{İsmail Yasin SÜLÜ1*}

\begin{abstract}
In this study, the composite parts subjected to tensile load were combined with a doubleacting adhesive connection and analyzed using the 3D finite element method (FEM). The joint design is important to ensure that the joint is durable, does not take up too much space and has a long service life. In the analysis, carbon / epoxy (AS4 / 3501-6) composite parts with different orientation angles were used and DP410 was used as adhesive. Models for numerical analysis were created using ANSYS 14.5 package program. Finite element analyzes were performed to determine the damage loads. In general, because the damages occur in the adhesive region, the stresses in all directions on the adhesive, shear stresses, von-Mises stress and peel stresses were obtained at the specified failure loads. As a result, the effects of orientation angles, overlap dimensions of the bonded area and adhesive layer were investigated. The most effective parameters were determined for the composite parts joined with embedded double-acting adhesive. Furthermore, it is stated that embedded adhesive connection is important for industrial applications.
\end{abstract}

Keywords: Non-linear analysis, finite element method (FEM), joint design, failure analysis, laminated composite

${ }^{1}$ İsmail Yasin SÜLÜ (Orcid ID: 0000-0002-2648-6294) İnönü Üniversitesi, Mühendislik Fakültesi, Makine Mühendisliği Bölümü, Malatya, Türkiye

*Sorumlu Yazar/Corresponding Author: İsmail Yasin SÜLÜ, e-mail: ismail.sulu@inonu.edu.tr

Geliș tarihi / Received: 08-10-2019

Kabul tarihi / Accepted: 28-11-2019 


\section{INTRODUCTION}

The classic single and double-lap joints are preferred for both joining and repairing in many industries. These bonding techniques are widely used for composites and metal parts. Due to ease of use, high strength, easy applicability and various other properties, the use of adhesives and composite parts in the industry is increasing. When joining composite parts, to form strong joints is important using adhesives. For this reason, there are many studies carried out regarding the joint in the literature.

Mechanical behavior of joint technique is one of the most important factors in determining the working life of composite parts and adhesive joint. Therefore, repair and bonding methods are important for composites. As a result, many studies have been done in the literature about the bonding techniques for composite pieces, their bonding regions and the mechanical behavior of single and double adhesive bonding units of composite pieces under different loads and parameters. Composite parts joined using methods with high joint efficiency is important.

Abdi et al. (2017) found that 'long' joints, whether equivalent or basic, tend to give the lowest adhesive failure stress. They compared the peel stress formula with the actual peel stress found by the FEA plane strain. The axial stiffness of the adhesive layer has been shown to be very high compared to the adherent axial stiffness. On the other hand, the efficiency of a functionally graded adhesive, adhesivebonded lap joint attachment points has been improved (Stein et. al, 2016; Guin and Wang, 2016). Ribeiro et al. (2016) examined adhesive bonding between aluminum and carbon epoxy composites, numerically and experimentally, taking into account the value of different adhesives and overlap length. A parametric study was performed regarding, which is generally the main geometric parameter, affects the strength of the joints. These studies are based on a detailed discussion of the predicted joint strength observed experimentally as a function of adhesive type and overlap length to provide design principles applicable to hybrid joints. In addition, repair and bonding studies were performed using composite patch and sheath (Sülü and Şahinaslan, 2016; Sülü, 2017). Failure estimates with adhesive bondlines of compositecomposite and composite-steel single joints were investigated (Tang et. al, 2013; Kim et. al, 2008; Katnam et. al, 2011; Khalili, 2009; Ariaee et. al, 2014; Reis et. al, 2005). Their mechanical behavior is explained under different loads.

Fawzia et al. (2006) examined the behavior of reinforced axially loaded flat steel sheets using carbon fiber reinforced polymer sheets. Two steel sheets were joined using the adhesive, followed by double belt splicing of carbon fiber sheet of different bond lengths. The behavior of the samples was also examined using non-linear FEA to estimate failure modes and load capacity. In addition, the bonding properties of the reinforced double belt joints under tension were investigated using experimental and numerical analysis (Fawzia et. al, 2010).A parametric study was performed with numerical modelling with CFRP bond lengths, adhesive maximum tensile and adhesive layer thickness variables. Moreover, the mechanical performance of steel / CFRP adhesive-bonded double-belt joints at high temperatures around the glass transition temperature of the adhesive was investigated (Nguyen et. al, 2011). Akpinar (2013) investigated the mechanical properties of aluminium or composite patches with different orientation angles in the overlapping areas under tensile force and double-belt connections. Six different types of joint specimens were subjected to tensile load.The effect of patch material on failure load and stress distribution was investigated experimentally and numerically. In another study, an experimental study was performed to characterize joint forces, peel stresses and failure modes at adhesive-bonded double-strap and reinforced single-coated glass-reinforced reinforced polymer (GFRP) joints (Lee et. al, 2009).It has been done in different studies about bonding techniques (Adin and Turgut, 2013; Adin and Temiz, 2014; Temiz et. al, 2015; Adin, 2017; Adin, 2012) 
In this study, DP 410 adhesive and composite parts with different orientation angles were used. The study was carried numerically out. Failure loads were determined considering different overlap sizes and orientation angles. Then, finite element analysis was performed to estimate failure loads and stress distributions were examined. Composite parts joined with adhesive joints under tensile load were examined with nonlinear FEA. All stresses peel stresses, shear stresses and the von-Mises stresses on the adhesive were obtained at failure the time. The objective of this study demonstrates the many advantages of composite parts joined with adhesive such as more practical and easy to use adhesive for industrial use, high strength.

\section{MATERIALS AND METHODS}

\section{D Non-Linear Finite Element Modeling of the Embedded Double-Lap Adhesive Joint}

The composite parts joined to the double-lap adhesive joint subjected to tensile load are shown in Figure 1. The composite parts are eight-layer carbon / epoxy (AS4 / 3501-6).In the finite element study, DP 410 was used as adhesives. The mechanical properties of the composite parts and the adhesive are respectively shown in Table 1 and Table 2.The true strain-stress behavior for the adhesives is shown in Figure 2.The different orientation angles shown in Table 3 were used.

Table 1. Material properties for AS4/3501-6 carbon/epoxy (Salih and Aydin, 2014; Daniel and Abot, 2000;Camponeschi,1990)

\begin{tabular}{cc}
\hline Properties & Carbon/epoxy (AS4/3501-6) \\
\hline $\mathrm{E}_{\mathrm{x}}(\mathrm{MPa})$ & 113600 \\
$\mathrm{E}_{\mathrm{y}}(\mathrm{MPa})$ & 9650 \\
$\mathrm{E}_{\mathrm{z}}(\mathrm{MPa})$ & 9650 \\
$\mathrm{G}_{\mathrm{xy}}(\mathrm{MPa})$ & 6000 \\
$\mathrm{G}_{\mathrm{yz}}(\mathrm{MPa})$ & 3800 \\
$\mathrm{G}_{\mathrm{xz}}(\mathrm{MPa})$ & 6000 \\
$v_{\mathrm{xy}}$ & 0.334 \\
$v_{\mathrm{yz}}$ & 0.54 \\
$v_{\mathrm{xz}}$ & 0.328 \\
$\mathrm{X}_{\mathrm{T}}(\mathrm{MPa})$ & 1720 \\
$\mathrm{Y}_{\mathrm{T}}(\mathrm{MPa})$ & 55.2 \\
$\mathrm{Z}_{\mathrm{T}}(\mathrm{MPa})$ & 55.2 \\
$\mathrm{X}_{\mathrm{C}}(\mathrm{MPa})$ & 1170 \\
$\mathrm{Y}_{\mathrm{C}}(\mathrm{MPa})$ & 207 \\
$\mathrm{Z}_{\mathrm{C}}(\mathrm{MPa})$ & 207 \\
$\mathrm{~S}_{\mathrm{xy}}(\mathrm{MPa})$ & 103 \\
$\mathrm{~S}_{\mathrm{yz}}(\mathrm{MPa})$ & 82.7 \\
$\mathrm{~S}_{\mathrm{xz}}(\mathrm{MPa})$ & 82.7 \\
\hline
\end{tabular}

Table 2. Material properties for DP 410 adhesive (Sülü et. al, 2015; Sulu and Temiz, 2018)

\begin{tabular}{cc}
\hline & DP 410 Adhesive \\
\hline $\mathrm{E}_{\mathrm{a}}(\mathrm{MPa})$ & 2567.45 \\
$v_{e}$ & 0.31 \\
$\sigma_{\psi}(\mathrm{MPa})($ Yield strength $)$ & 38 \\
$\sigma_{\tau}(\mathrm{MPa})($ Ultimate tensile strength $)$ & 40.79 \\
$\varepsilon_{\tau}\left(\mathrm{mm} \cdot \mathrm{mm}^{-1}\right)($ Ultimate tensile strain $)$ & 0.027 \\
\hline
\end{tabular}


Table 3. Orientation angles used in the studies

\begin{tabular}{c}
\hline Orientation angles $\left({ }^{0}\right)$ \\
{$\left[0^{0}\right]_{8 \mathrm{~S}}$} \\
{$\left[15^{0} /-15^{0} / 15^{0} /-15^{0}\right]_{\mathrm{S}}$} \\
{$\left[30^{0} /-30^{0} / 30^{0} /-30^{0}\right]_{\mathrm{S}}$} \\
{$\left[45^{0} /-45^{0} / 45^{0} /-45^{0}\right]_{\mathrm{S}}$} \\
{$\left[60^{0} /-60^{0} / 60^{0} /-60^{0}\right]_{\mathrm{S}}$} \\
{$\left[75^{0} /-75^{0} / 75^{0} /-75^{0}\right]_{\mathrm{S}}$} \\
{$\left[90^{0}\right]_{8 \mathrm{~S}}$} \\
\hline
\end{tabular}

The total thickness of the carbon fibre-reinforced composite parts is $8 \times 0.2 \mathrm{~mm}$, the thickness of each layer is $0.2 \mathrm{~mm}$ and the adhesive thickness is $0.2 \mathrm{~mm}(\mathrm{t})$. The length of the composite parts was $62.5 \mathrm{~mm}(\mathrm{~L})$ and adherent lengths were respectively $10 \mathrm{~mm}, 15 \mathrm{~mm}, 20 \mathrm{~mm}\left(\mathrm{~L}_{1}\right)$.

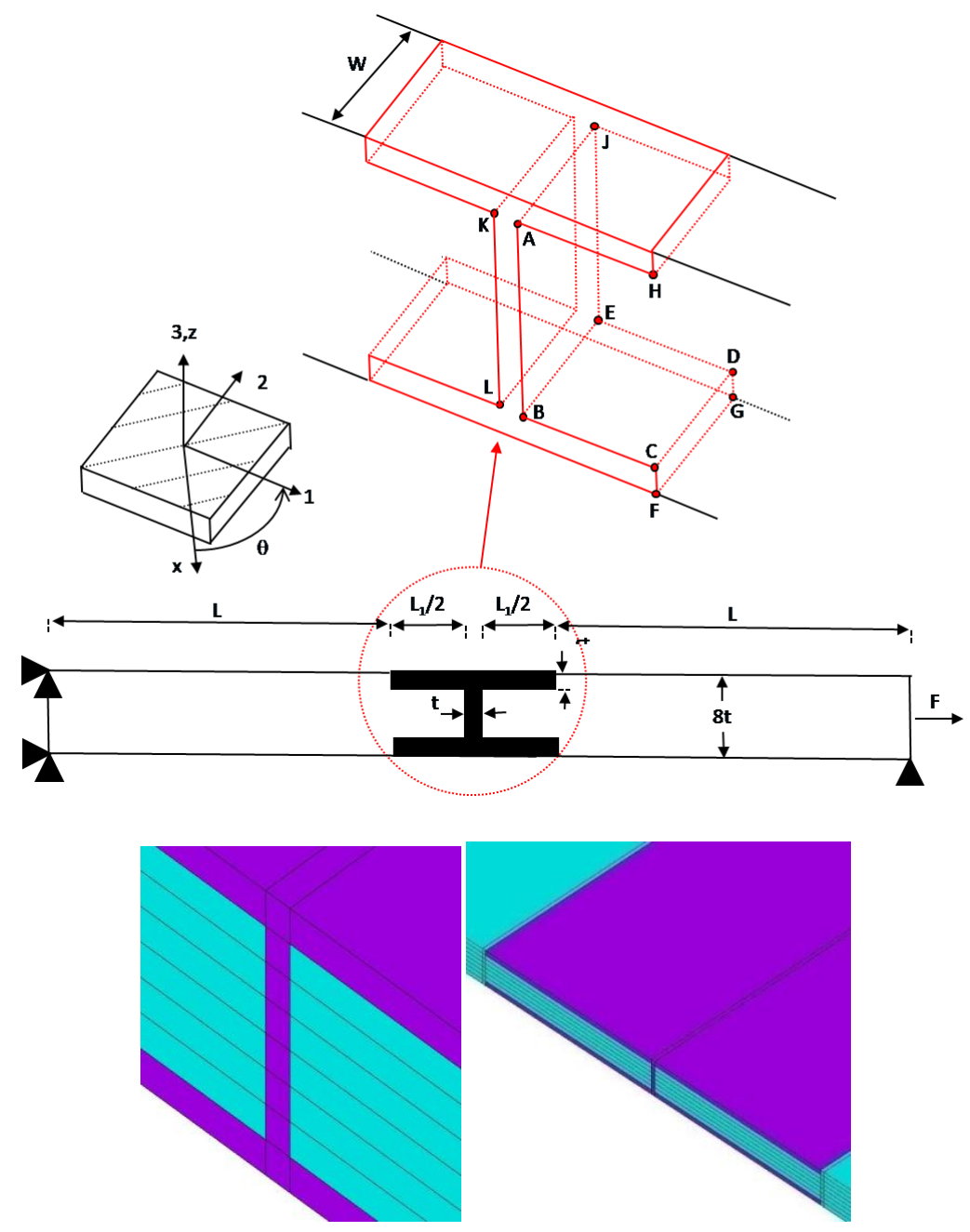

Figure 1.Composite parts joined with embedded double-lap adhesive joint 


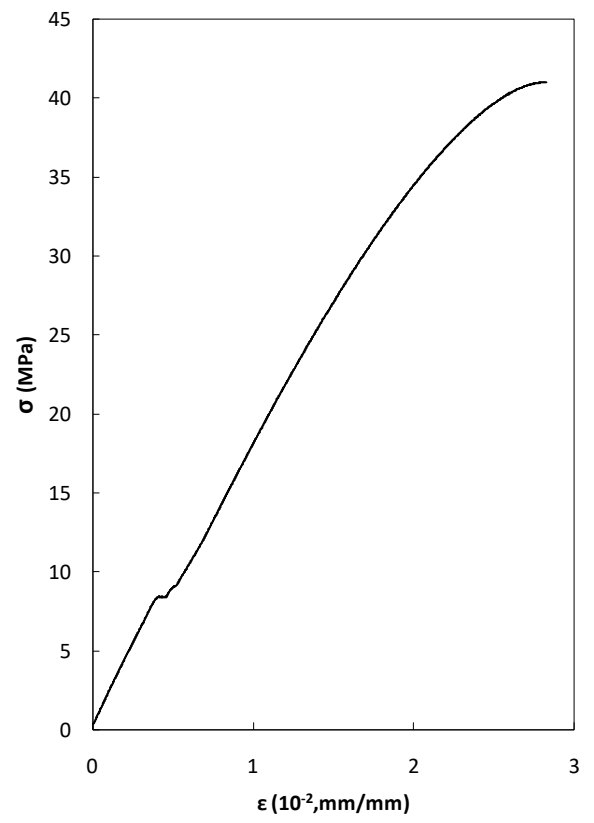

Figure 2.Tensile stress-strain curve of DP 410 adhesive (Sülü et. al, 2015; Sulu and Temiz, 2018)

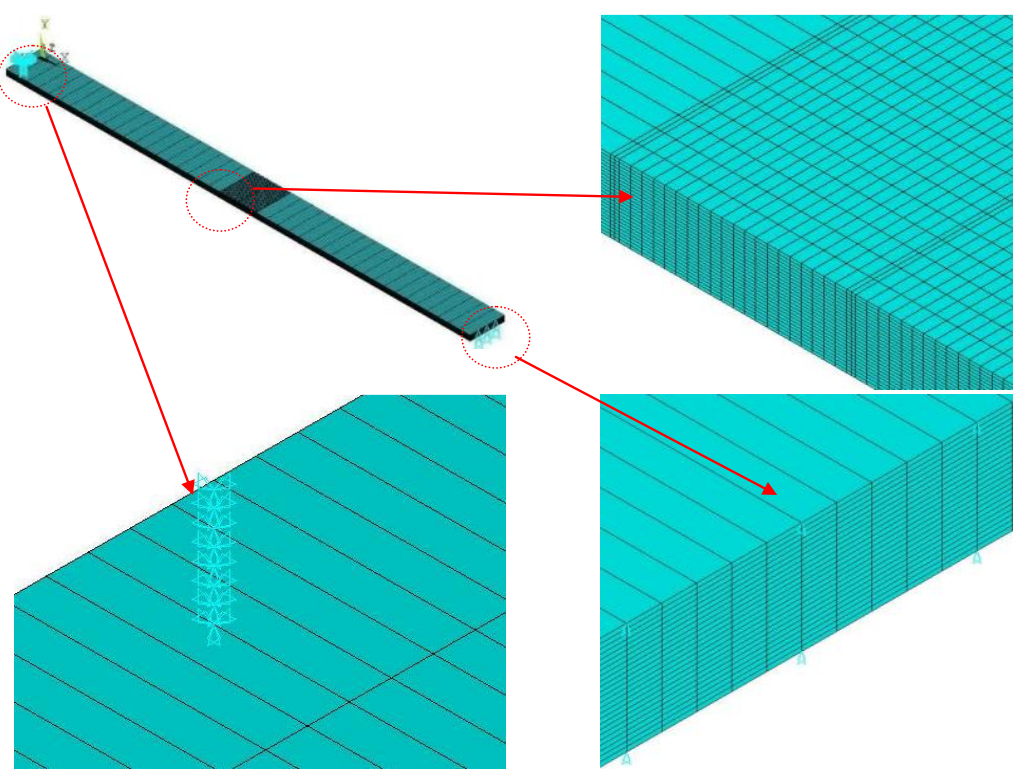

Figure 3.Boundary condition and mesh details

In the working, composite parts connected with double-lap adhesive joint subjected to tensile load were simulated by FEM. Three-dimensional non-linear FEM was generated during the analysis of composite parts joined using double-adhesive joint. In the ANSYS, SOLID186, isoperimetric quadrangular elements with 20 nodes, were used. The SOLID186 element is defined by twenty nodes with three degrees of freedom in each node for translation in the nodal all directions. In Figure 3, the joint configuration, boundary conditions and mesh details discussed in this study were shown. The first end of the composite pieces joined with the double-adhesive joint is fixed in the nodal all directions and the other end in the nodal y-direction. Composite parts bonded with the embedded double-lap adhesive joint were subjected to tensile load and stress analyses were carried out, and stress distributions for all the layers of the composite parts were calculated by taking into consideration Von-Mises failure criteria for adhesives and Tsai-wu failure criteria for composites (Sülü et. al, 2015; Sulu and Temiz, 2018; Ozel et. al, 2014; Sülü, 2017; Sülü, 2016) 


\section{RESULTS AND DISCUSSION}

\section{Effect of Adhesive Dimensional and Orientation Angles on Stress Distribution}

The stress distributions of composite parts bonded with the embedded double lap adhesive joint under tensile load were compared for $15 \mathrm{~mm}$ overlap length and for $\left[0^{0}\right]_{8 \mathrm{~s}},\left[15^{0} /-15^{0} / 15^{0} /-15^{0}\right]_{\mathrm{s}}$, $\left[30^{0} /\right.$ $\left.30^{0} / 30^{0} /-30^{0}\right]_{\mathrm{s}},\left[45^{0} /-45^{0} / 45^{0} /-45^{0}\right] \mathrm{s},\left[60^{0} /-60^{0} / 60^{0} \%-60^{0}\right] \mathrm{s},\left[75^{0} /-75^{0} / 75^{\%} /-75^{0}\right] \mathrm{s},\left[90^{0}\right]_{8 s}$ orientation angles were analyzed. On the bonding surfaces, there were several bonding lines in the bonding zone of the joint, with the embedded double lap adhesive joint (see Figure 1). As shown in Figure 4, von Mises stress distributions along some bonded-lines were compared and stress on A-B was greater than K-L. Also, the stresses on A-H and B-C were very close. In this case, the stress lines to be examined were determined. Stress distributions of each edge bond line in the determined region were different. So, bond line stresses where stresses are maximum and critical are examined as shown in Figure 4 (c). The stress of von-Mises equivalent in the A-B ligament line was maximum. Therefore, in this study, all stress distributions plotted were for the A-B ligament line in the adhesive region.

Stress distributions under the tensile load of the joint are given in Figures 5 and 6. With the embedded double lap adhesive joint, the joint tension is generally higher in the A-B line. This was because the A-B line was exposed directly to high load and the load-bearing capacity of the orientation angles was better due to the high strain at failure, which enables the applied load to be transferred to a wider area of the over-lap and the joint to be stronger.

Stresses in all directions, the von-Mises stresses and shear stresses on the adhesive were numerically obtained using tensile loads. Figures 5 and 6 , the stresses obtained on the adhesives as a result of bonding the composite parts to the adhesive can be seen.

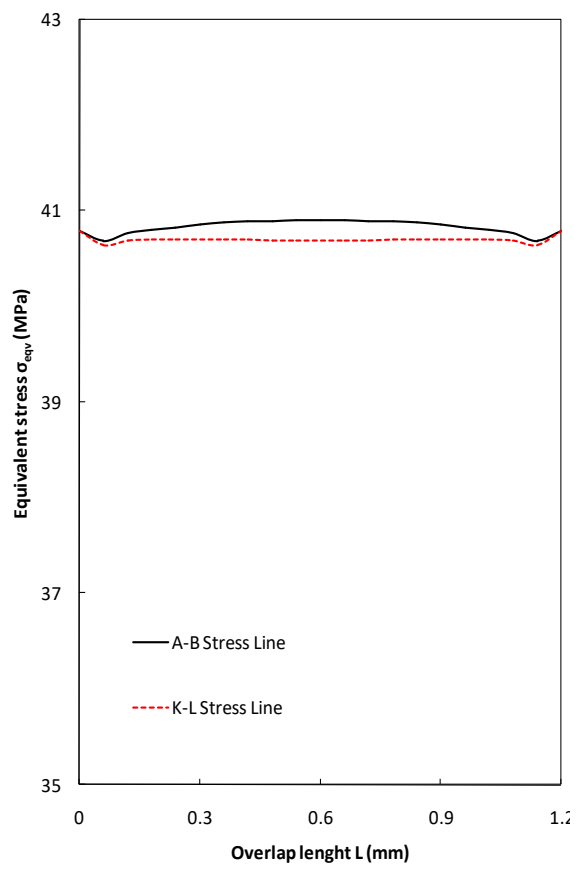

(a)

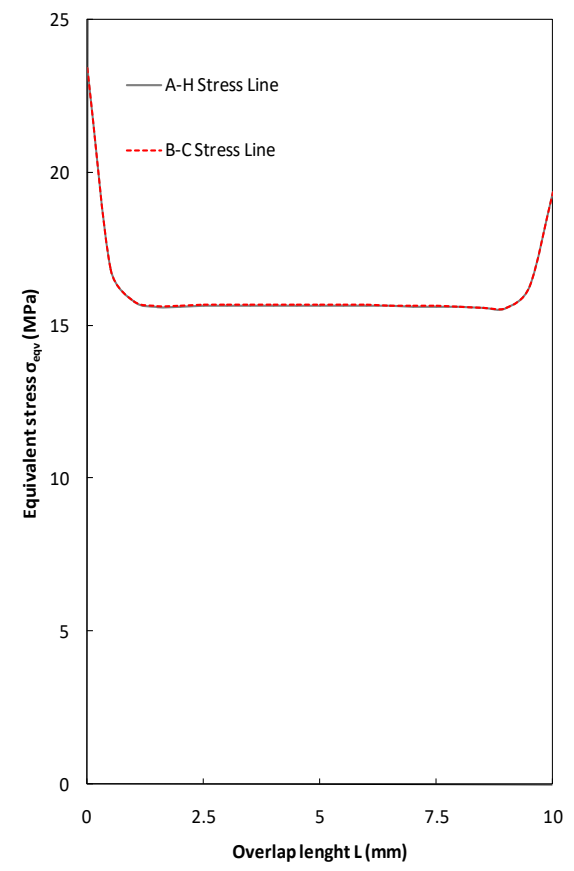

(b)

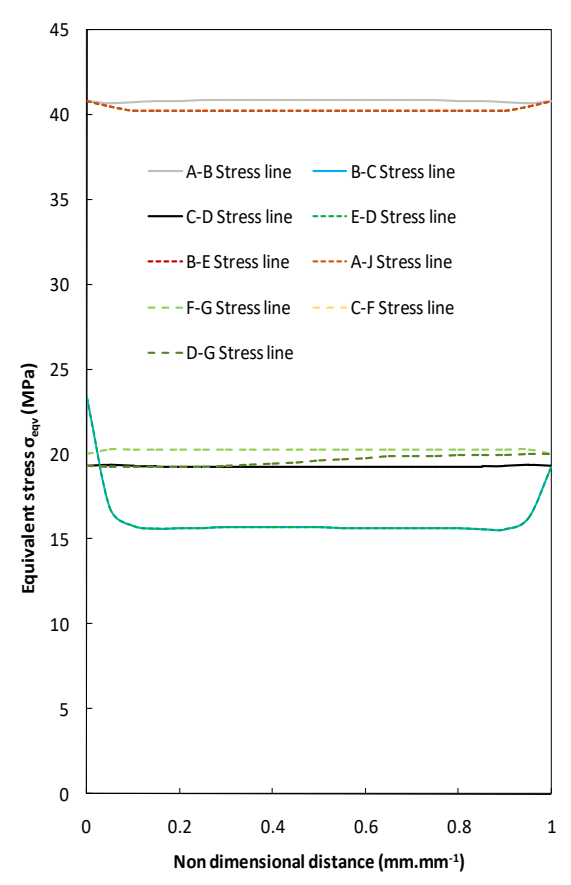

(c)

Figure 4.The von-Mises tensile is distributed along the different tensile line (shown in Figure 1: adhesive region compared to $20 \mathrm{~mm}$ patch length and $\left[90^{0}\right]_{8 \mathrm{~S}}$ )

The effects of the orientation angles on the adhesive layers are shown in Figure 5. It can be seen in the figures that the highest stresses subjected to the tensile load at the ends of the adhesive zone are those occurring in the line A-B. In general, it was observed that maximum $\sigma_{\mathrm{x}}, \sigma_{\mathrm{y}}$ and $\sigma_{\mathrm{z}}$ on adhesive 
layer were at composite parts with $\left[90^{\circ}\right]_{8 s}$ orientation angle adhesively joined. In the same way, the vonMises stress was maximum at composite parts with $\left[90^{\circ}\right]_{85}$ orientation angle adhesively joined. However, $\sigma_{\mathrm{x}}, \sigma_{\mathrm{y}}, \sigma_{\mathrm{z}}$ and the von-Mises stress on adhesive layer were minimum at composite parts with

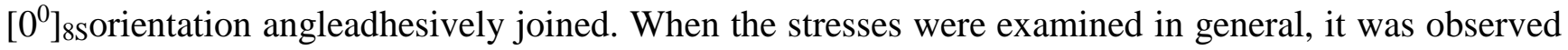
that the stresses decreased from the ends part to the middle part on the adhesive zone.

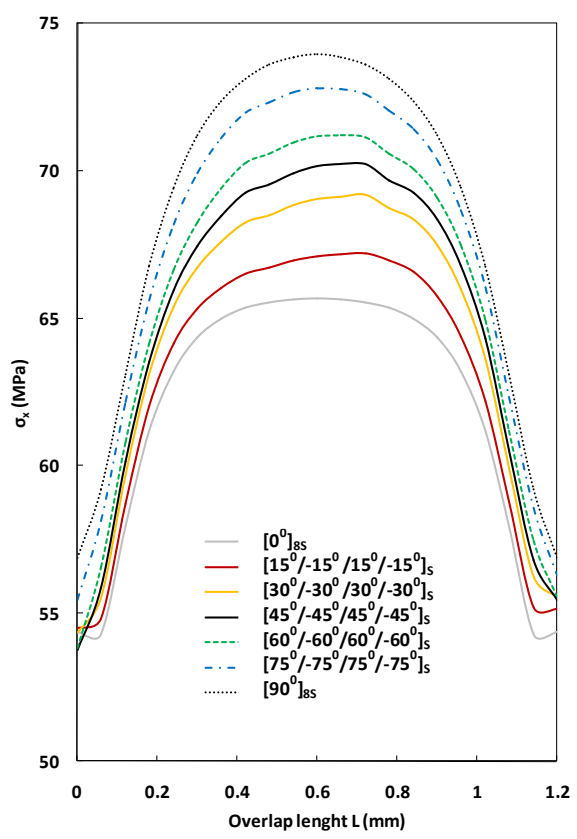

(a)

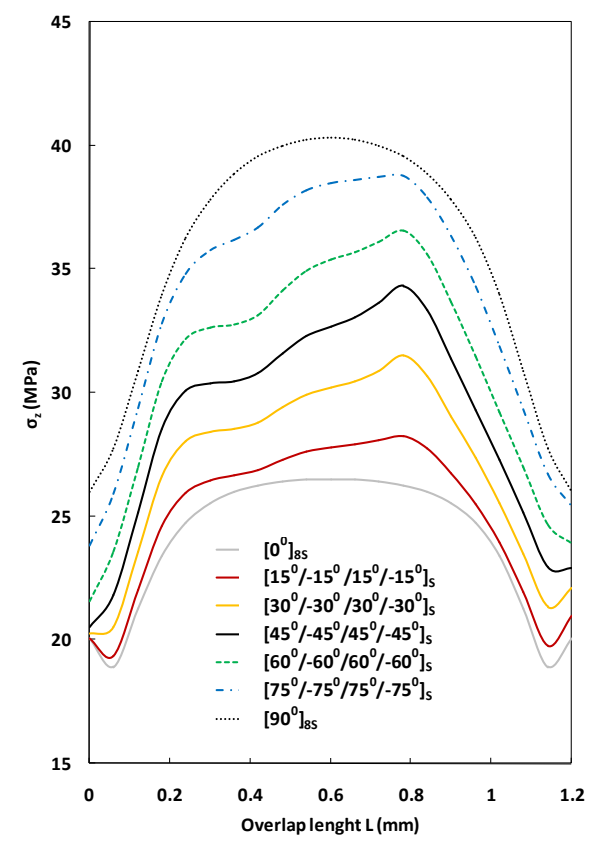

(c)

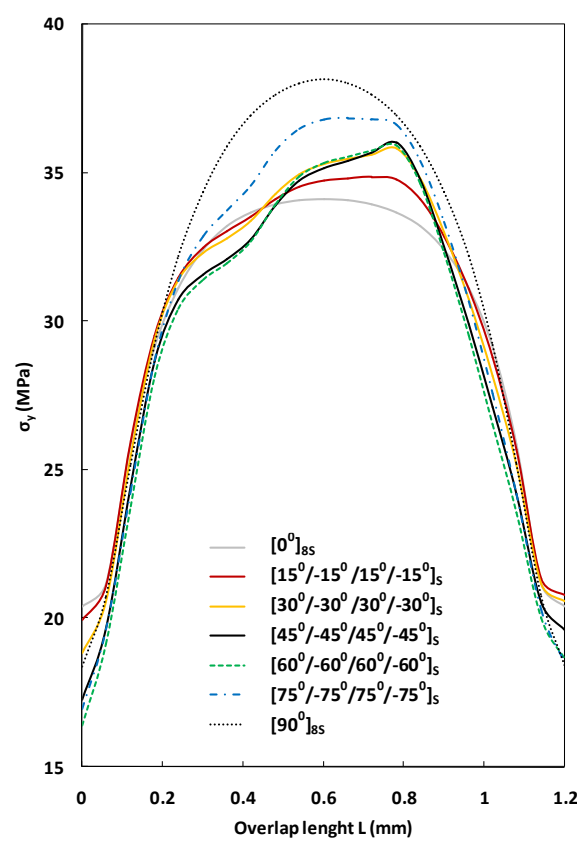

(b)

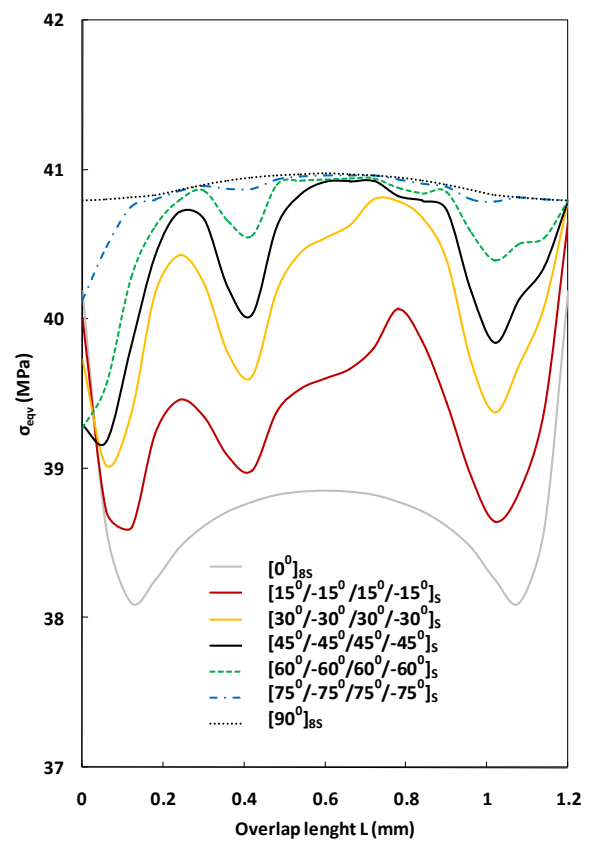

(d)

Figure 5.Stress distributions for a patch length of $15 \mathrm{~mm}$ relative to all orientations along the A-B stretch line on the adhesive, a) $\sigma_{\mathrm{x}}, \mathrm{b}$ ) $\left.\left.\sigma_{\mathrm{y}}, \mathrm{c}\right) \sigma_{\mathrm{z}}, \mathrm{d}\right) \sigma_{\text {eqv }}$ )

In Figure 6, the effects on shear stresses of orientation angles were shown. In general, it was stated that maximum $\sigma_{x y}$ on adhesive layer were composite parts with $\left[0^{0}\right]_{8 s}$ orientation angle joined adhesively, maximum $\sigma_{\mathrm{xz}}$ were at composite parts with $\left[75^{\circ} /-75^{0} / 75^{0} /-75^{0}\right]_{\mathrm{s}}$ orientation angle joined and maximum $\sigma_{\mathrm{yz}}$ were at composite parts with $\left[45^{0} /-45^{0} / 45^{0} /-45^{0}\right]_{\mathrm{S}}$ orientation angle adhesively joined 


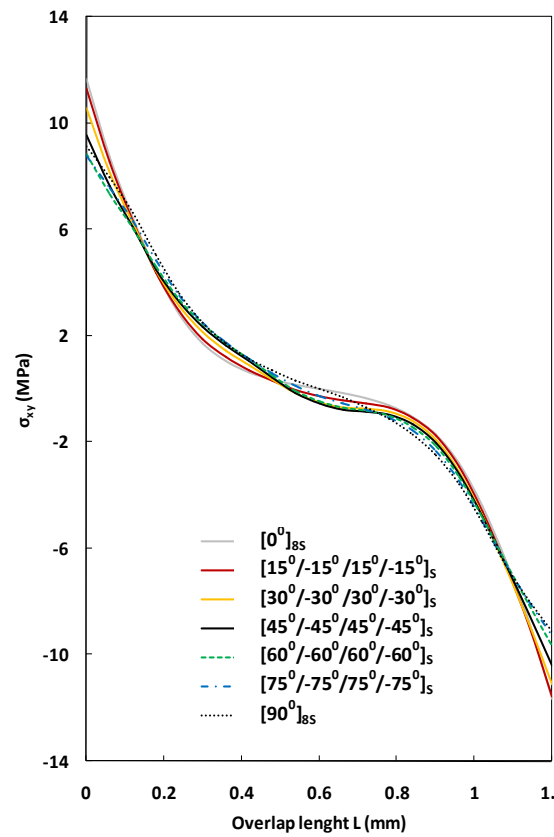

(a)

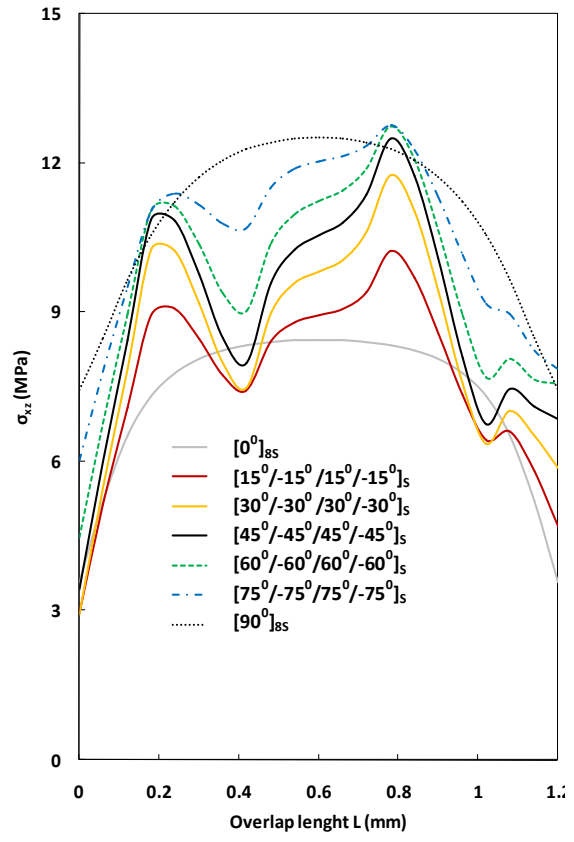

(b)

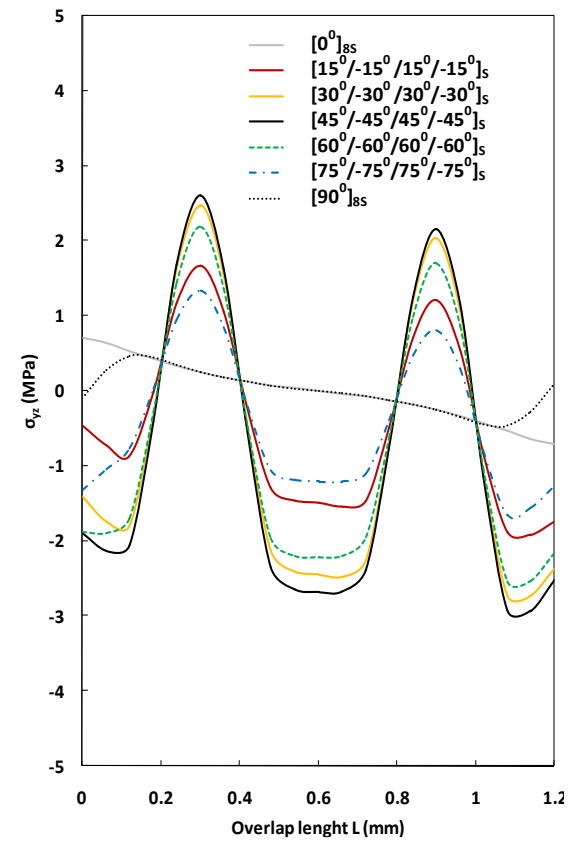

(c)

Figure 6.Shear stress for a patch length of $15 \mathrm{~mm}$ relative to all orientations along the A-B stretch line on the adhesive, a) $\left.\left.\sigma_{x y}, b\right) \sigma_{x z}, c\right) \sigma_{y z}$ )

As shown in Figure 7, for $15 \mathrm{~mm}$ adhesive length, the peel and shear stresses distributions at B-C line were calculated for all orientation angles. The peel and shear $\sigma_{\mathrm{yz}}$ stress distributions for $\left[90^{0}\right]_{8 \mathrm{swere}}$ greater than others. In the other hand, for $\left[0^{0}\right]_{8 s}$ orientation angle, these stresses were minimum. Moreover, although shear $\sigma_{\mathrm{xz}}$ stress distributions for $\left[0^{0}\right]_{8 \mathrm{~s}}$ were greater than others, it was minimum for $\left[60^{\circ} /-60^{\circ} / 60^{\circ} /-60^{0}\right]_{\mathrm{s}}$ orientation angle.

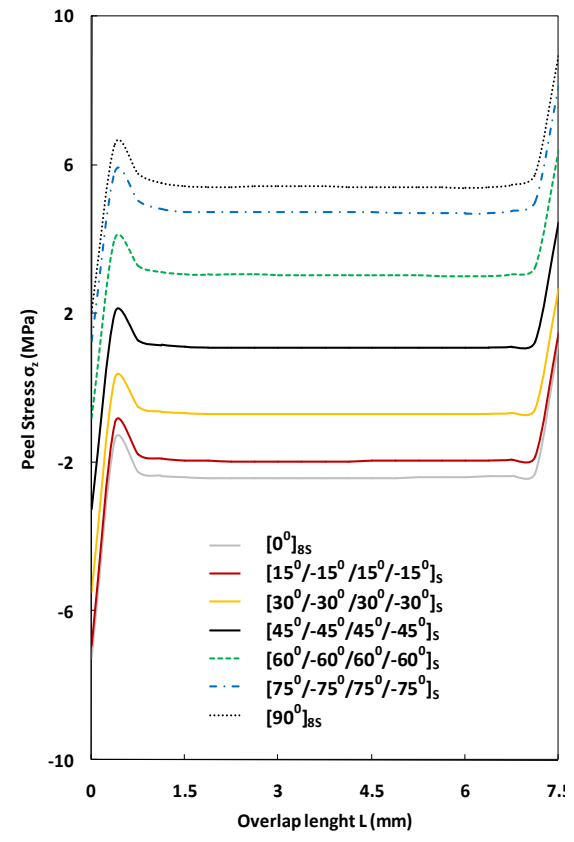

(a)

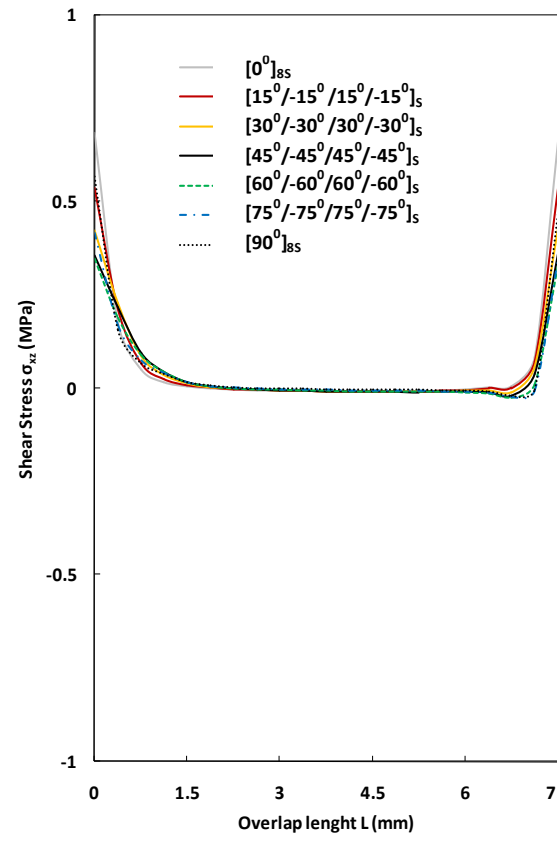

(b)

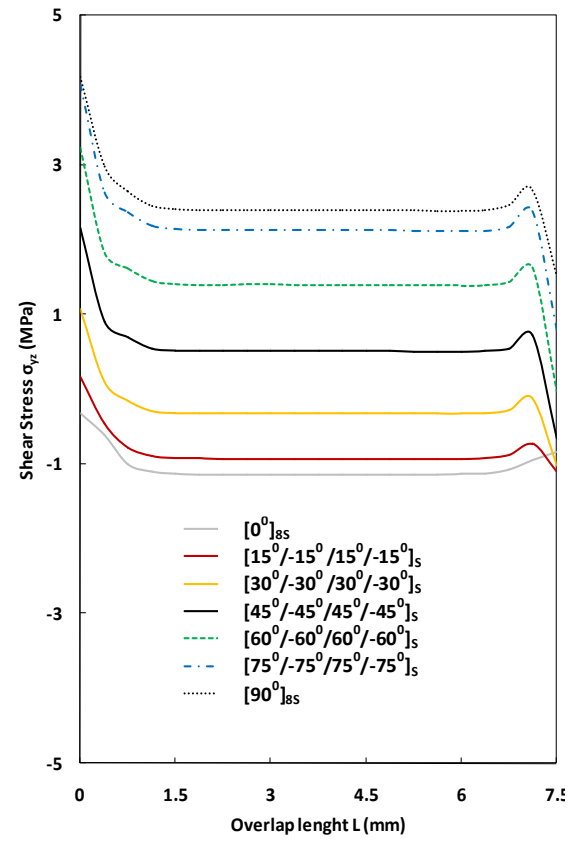

(c)

Figure 7. For $15 \mathrm{~mm}$ of adherent length, comparison of peel and shear stress distributions for all orientation angles along B-C on adhesive region, a) Peel stress $\sigma_{\mathrm{z}}, \mathrm{b}$ ) Shear stress $\sigma_{\mathrm{xz}}, \mathrm{c}$ ) Shear stress $\sigma_{\mathrm{yz}}$ 


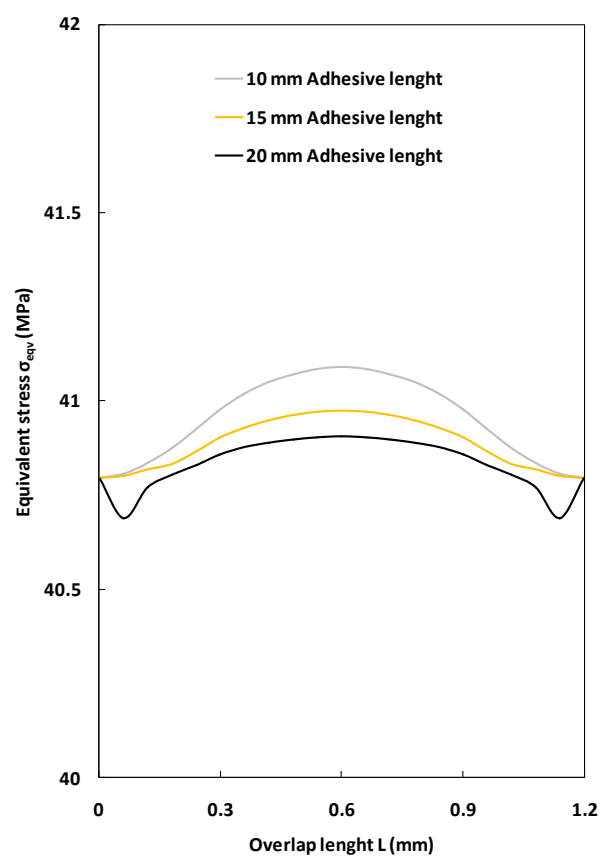

Figure 8. Comparison of the von-Mises stress distributions for the different over-lap length (shown in Figure 1) on adhesive region for $\left[90^{0}\right]_{8 \mathrm{~S}}$

In Figure 8, the von-Mises stress distributions were plotted for different over-lap lengths with $\left[90^{0}\right]_{8 s}$ orientation angle. For $10 \mathrm{~mm}$ adhesive length, the von-Mises stress distribution was greater than others. The stress distribution for $20 \mathrm{~mm}$ adhesive length was smaller than others. Then, it could say that adhesive length was an important parameter for this study.

\section{The Effect of Orientation Angles and Adhesive Size on Failure Load}

In Table 4, the effects of the failure loads of the composite parts combined with the embedded double lap adhesive joint for different parameters were shown. The strain-stress behavior for the adhesives was shown in Figure 2. The ultimate strain $\left(\varepsilon^{*}\right)$ given in Table 2 was used to predict the failure load for the adhesive. The equivalent strain $\left(\varepsilon_{\text {eqv }}\right)$ and stress $\left(\sigma_{\text {eqv }}\right)$ were obtained using the von-Mises yield criterion and it was assumed that the failure occurred when the equivalent strain $\left(\varepsilon_{\text {eqv }}\right)$ calculated at any point of the adhesive layer reached the ultimate strain. A solution in FEA considering nonlinear material behavior was reached by dividing the total load in steps to track the equilibrium paths and iterating to a converged solution at each load increment. Hence, a load of $0.5 \mathrm{~N} \cdot \mathrm{mm}^{-2}$ per $\mathrm{mm}^{2}$ area was applied at each load step for all joint types. The remaining load was then applied in the last step (Sulu and Temiz, 2018; Sülü, 2017; Sülü, 2016; Temiz, 2006).

The von-Mises stresses, stresses in all direction, shear stresses and peel stress on adhesive were numerically calculated using failure load. The stresses on all elements of bonding interfaces in Figure 4(c) were obtained at failure loads, and the highest stress distributions on the bonding lines occurred on the A-B line. During the studies, this was the reason for examining stresses on this line.

When Table 4 was examined, the failure loads of all bonded points with a $20 \mathrm{~mm}$ adhesive length were greater than the others. The maximum predicted failure loads of the composite parts bonded with the embedded double-wound adhesive joint were composite parts with orientation angles of $\left[90^{0}\right]_{85}$ for all adhesive lengths. The minimum predicted failure loads were composite parts with $\left[0^{0}\right]_{8 s}$ orientation angles at all adhesive lengths. In all adhesive lengths, composite parts with $\left[30^{\circ} /-30^{0} / 30^{\circ} /-30^{0}\right]_{\mathrm{s}},\left[45^{0} /-\right.$ 
$\left.45^{0} / 45^{0} /-45^{0}\right]_{\mathrm{S}},\left[60^{0} /-60^{\circ} / 60^{0} /-60^{0}\right]_{\mathrm{S}}$ orientation angles had the same failure loads. But, they didn't have the same stress distributions. When adhesive region expanded, failure load increased.

Table 4. Results of numerical analysis for double-lap joint, in case of using DP 410

\begin{tabular}{|c|c|c|c|}
\hline Specimen No. & Adhesive length $\mathrm{L}_{1}$ and width $\mathrm{W}(\mathrm{mm})$ & Orientation angles & Failure Load F $(\mathrm{N})$ \\
\hline 1 & \multirow[t]{7}{*}{ 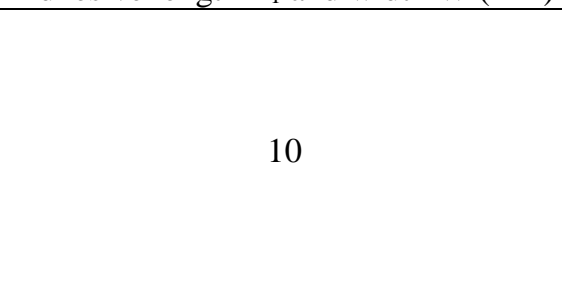 } & {$\left[0^{0}\right]_{8 \mathrm{~s}}$} & 7744.0 \\
\hline 2 & & {$\left[15^{0} /-15^{0} / 15^{0} /-15^{0}\right] \mathrm{s}$} & 7872.0 \\
\hline 3 & & {$\left[30^{\circ} /-30^{\circ} / 30^{\circ} /-30^{\circ}\right]_{\mathrm{s}}$} & 7808.0 \\
\hline 4 & & {$\left[45^{\circ} /-45^{0} / 45^{0} /-45^{0}\right] \mathrm{s}$} & 7808.0 \\
\hline 5 & & {$\left[60^{\circ} /-60^{\circ} / 60^{\circ} /-60^{0}\right] \mathrm{s}$} & 7808.0 \\
\hline 6 & & {$\left[75^{\circ} /-75^{0} / 75^{\circ} /-75^{0}\right]_{\mathrm{s}}$} & 7872.0 \\
\hline 7 & & {$\left[90^{\circ}\right]_{8 \mathrm{~S}}$} & 8064.0 \\
\hline 8 & \multirow{7}{*}{15} & {$\left[0^{0}\right]_{8 \mathrm{~S}}$} & 11520.0 \\
\hline 9 & & {$\left[15^{0} /-15^{0} / 15^{0} /-15^{0}\right]_{\mathrm{s}}$} & 11712.0 \\
\hline 10 & & {$\left[30^{\circ} /-30^{\circ} / 30^{\circ} /-30^{\circ}\right]_{\mathrm{s}}$} & 11904.0 \\
\hline 11 & & {$\left[45^{\circ} /-45^{0} / 45^{0} /-45^{0}\right]_{\mathrm{s}}$} & 11904.0 \\
\hline 12 & & {$\left[60^{\circ} /-60^{\circ} / 60^{\circ} /-60^{0}\right]_{\mathrm{s}}$} & 11904.0 \\
\hline 13 & & {$\left[75^{\circ} /-75^{0} / 75^{0} /-75^{0}\right] \mathrm{s}$} & 12096.0 \\
\hline 14 & & {$\left[90^{\circ}\right]_{8 \mathrm{~S}}$} & 12288.0 \\
\hline 15 & \multirow{7}{*}{20} & {$\left[0^{0}\right]_{8 \mathrm{~S}}$} & 15232.0 \\
\hline 16 & & {$\left[15^{0} /-15^{0} / 15^{0} /-15^{0}\right] \mathrm{s}$} & 15360.0 \\
\hline 17 & & {$\left[30^{\circ} /-30^{0} / 30^{0} /-30^{0}\right]_{\mathrm{S}}$} & 15872.0 \\
\hline 18 & & {$\left[45^{\circ} /-45^{0} / 45^{\circ} /-45^{0}\right]_{\mathrm{s}}$} & 15872.0 \\
\hline 19 & & {$\left[60^{\circ} /-60^{\circ} / 60^{\circ} /-60^{\circ}\right] \mathrm{s}$} & 16000.0 \\
\hline 20 & & {$\left[75^{\circ} /-75^{0} / 75^{0} /-75^{0}\right] \mathrm{s}$} & 16128.0 \\
\hline 21 & & {$\left[90^{0}\right]_{8 \mathrm{~S}}$} & 16384.0 \\
\hline
\end{tabular}

\section{CONCLUSIONS}

In this study, composite parts connected with buried double-lap adhesive joint subjected to tensile load were examined using finite element method. The results are as follows:

- The stresses of the bond line A-B are greatest.

- The effects of different adhesion lengths and different orientation angles were investigated and the breakdown loads of all joints connected with a $20 \mathrm{~mm}$ adhesive length were greater than those shown in Table 4.

- As shown in Table 4, the maximum predicted failure loads of the bonding with the embedded double lap adhesive joint were obtained and composite parts with $\left[90^{0}\right]_{8 s}$ were higher failure loads than others. - $\sigma_{\mathrm{x}}, \sigma_{\mathrm{y}}, \sigma_{\mathrm{z}}$ and the von-Mises stresses were maximum on adhesive layer for $\left[90^{\circ}\right]_{8 \text { sorientation angle, as }}$ shown in the Figures $5 \mathrm{a}$ to $5 \mathrm{~d}$.

- As shown in the Figures $6 a$ to $6 c, \sigma_{x y}$ on adhesive layer were maximum when composite parts with $\left[0^{0}\right]_{8 s}$ orientation angle were joined by using adhesive, $\sigma_{\mathrm{xz}}$ were maximum when composite parts with $\left[75^{\circ} /-75^{0} / 75^{\%} /-75^{0}\right]_{\mathrm{S}}$ orientation angle are joined and $\sigma_{\mathrm{yz}}$ were maximum when composite parts with $\left[45^{\circ} /-45^{0} / 45^{\circ} /-45^{0}\right]_{\mathrm{S}}$ orientation angle were joined.

- In the B-C bond line, the peel and shear $\sigma_{\mathrm{yz}}$ stress distributions for $\left[90^{0}\right]_{8 \mathrm{~s}}$ were greater than others. The shear $\sigma_{\mathrm{xz}}$ stress distributions for $\left[0^{0}\right]_{8 \mathrm{~s}}$ were greater than others.

- Generally, it could be said that $\left[0^{0}\right]_{8 \mathrm{~s}},\left[90^{0}\right]_{8 \mathrm{~s}}$ orientation angles and all adhesive length were the most effective parameters.

- In general, the failures occurred in the adhesive region. 


\section{REFERENCES}

Abdi H, Papadopoulos J, Nayeb-Hashemi H, Vaziri A, 2017. Enhanced elastic-foundation analysis of balanced single lap adhesive joints. International Journal of Adhesion \& Adhesives, 72: 80-91.

Stein N, Mardani H, Becker W, 2016. An efficient analysis model for functionally graded adhesive single lap joints. International Journal of Adhesion \& Adhesives, 70: 117-125.

Guin W E, Wang J, 2016. Theoretical model of adhesively bonded single lap joints with functionally graded adherents. Engineering Structures, 124: 316-332.

Ribeiro T E A, Campilho R D S G, da Silva L FM, Goglio L, 2016. Damage analysis of compositealuminium adhesively-bonded single-lap joints. Composite Structures, 136: 25-33.

Sülü İsmail Yasin, Şahinaslan Apdulmutalip, 2016. Experimental failure testing and repair of internal pressurized composite pipes using different fracture models. Materials Testing, 58- 9: 788-793.

Sülü İsmail Yasin, 2017. Mechanical behavior of internal pressurized composite pipes jointed with embedded tubular sleeves. Materials Testing,59-3: 272-277.

Tang J H, Sridhar I, Srikanth N, 2013. Static and fatigue failure analysis of adhesively bonded thick composite single lap joints. Composites Science and Technology, 86: 18-25.

Kim K S, Yi Y M, Cho G R, Kim C G, 2008. Failure prediction and strength improvement of unidirectional composite single lap bonded joints. Composite Structures, 82: 513-520.

Katnam K B, Comer A J, Stanley W F, Buggy M, Ellingboe A R, Young T M, 2011.Characterisingprepreg and non-crimp-fabric composite single lap bonded joints. International Journal of Adhesion \& Adhesives, 31: 679-686.

Khalili S M R, Jafarkarimi M H, Abdollahi M A, 2009. Creep analysis of fibre reinforced adhesives in single lap joints_-Experimental study. International Journal of Adhesion \& Adhesives, 29: 656661.

Ariaee S, Tutunchi A, Kianvash A, Entezami A A, 2014. Modeling and optimization of mechanical behavior of bonded composite-steel single lap joints by response surface methodology. International Journal of Adhesion \& Adhesives, 54: 30-39.

Reis P N B, Antunes F J V, Ferreira J A M, 2005. Influence of superposition length on mechanical resistance of single-lap adhesive joints. Composite Structures, 67: 125-133.

Fawzia Sabrina, Al-Mahaidi Riadh , Zhao Xiao-Ling, 2006. Experimental and finite element analysis of a double strap joint between steel plates and normal modulus CFRP. Composite Structures, 75: 156-162.

Fawzia Sabrina, Zhao Xiao-Ling, Al-Mahaidi Riadh, 2010. Bond-slip models for double strap joints strengthened by CFRP. Composite Structures, 92: 2137-2145.

Nguyen Tien-Cuong, Bai Yu, Zhao Xiao-Ling, Al-Mahaidi Riadh, 2011. Mechanical characterization of steel/CFRP double strap joints at elevated temperatures. Composite Structures, 93: 1604-1612.

Akpinar Salih, 2013. Effects of laminate carbon/epoxy composite patches on the strength of doublestrap adhesive joints: Experimental and numerical analysis. Materials and Design, 51: 501-512.

Lee H K, Pyo S H, Kim B R, 2009. On joint strengths, peel stresses and failure modes in adhesively bonded double-strap and supported single-lap GFRP joints. Composite Structures, 87: 44-54.

Adin Hamit, Turgut Aydın , 2013. The Effects of Width on the Strength of Adhesively Bonded Z Joints Subjected to Tensile Loads. The Journal of Adhesion, 89:1-18.

Adin Hamit, Temiz Şemsettin, 2014. Experimental and Numerical Strength Analysis of Double Lap Joints Subjected to Tensile Loads. Materials Testing, 56- 2: 160-168. 
Temiz Semsettin, Sülü Ismail Yasin, Adin Hamit, 2015. Behaviour Of Bi-Adhesive in Double-Strap Joint With Embedded Patch Subjected to Bending. Journal of Theoretical and Applied Mechanics, 45-3: 83-96

Adin Hamit, 2017. Effect of overlap length and scarf angle on the mechanical properties of different adhesive joints subjected to tensile loads. Materials Testing, 59-6: 536-546.

Adin Hamit, 2012. The effect of angle on the strain of scarf lap joints subjected to tensile loads. Applied Mathematical Modeling, 36-7: 2858-2867.

Salih A, Aydin M D, 2014. 3-D non-linear stress analysis on the adhesively bonded composite joint under bending moment. International Journal of Mechanical Sciences, 81: 149-157.

Daniel I M, Abot J L, 2000. Fabrication testing and analysis of composite sandwich beams. Composites Science and Technology, 60: 2455-2463.

Camponeschi E T, 1990. Compression Response of Thick-Section Composite Materials. ReportDTRCSME-90/60, David Taylor Research Center, Annapolis, USA.

Sülü İ Y, Temiz Ş, Aydin M D, 2015. Layer effects of multi-layered face to face adhesively bonded composite pipes subjected to internal pressure.Academic Journal of Science, 04: No. 3, 195-202.

Sulu Ismail Yasin, Temiz Semsettin, 2018. Failure and stress analysis of internal pressurized composite pipes joined with sleeves. Journal of Adhesion Science and Technology, 32:8, 816-832.

Ozel A, YaziciB, AkpinarS, Aydin M D, Temiz Ş, 2014. A study on the strength of adhesively bonded joints with different adherends. Composites Part B: Engineering, 62: $167-174$.

Sülü İsmail Yasin, 2017. Mechanical behavior of internal pressurized composite pipes jointed with embedded tubular sleeves. Materials Testing, 59-3: pages 272-277.

Sülü İsmail Yasin, 2016. Stress Analysis of Multi-Layered Hybrid Composite Pipes Subjected to Internal Pressure. International Journal of Engineering \& Applied Sciences, Vol.8- Issue 4: 87-98.

Temiz S, 2006.Application of bi-adhesive in double-strap joints subjected to bending moment. Journal of Adhesion Science and Technology, 20: 1547-1560. 